\title{
EFFECTS OF FLOOR SLABS ON THE FLEXURAL STRENGTH OF BEAMS IN REINFORCED CONCRETE BUILDINGS
}

\author{
Toshimi Kabeyasawa ${ }^{1}$, Toshikazu Kabeyasawa ${ }^{2}$ \\ and Hiroshi Fukuyama ${ }^{3}$
}

(Submitted February 2017; Reviewed July 2017; Accepted July 2017)

\begin{abstract}
The effects of floor slabs on the flexural strength of beams in reinforced concrete buildings under seismic action were verified through tests of frame assembly specimens. A series of experimental and analytical investigations were conducted from 2010 to 2014 in order to further validate the current design practices in Japan. Loading methods in the past beam component tests were reviewed with probable effects of floor slabs. A special loading set-up was used for the frame assembly specimens consisting of four columns and four beams with lengths of one span and two half spans in two directions. The four columns were loaded laterally and independently at mid-height of the upper storey and supported at mid-height of the lower storey with pinfixed and pin-roller so that axial elongation of the beams and slab would not be constrained by the lateral forces. It has been found from these new loading tests that the tensile stresses in the floor slab reinforcing bars are generally uniform at the beam critical sections and up to the full slab width for the flexural strength when the slab is subjected to tension bending around one percent storey drift, which is much wider than assumed in the current design evaluation.
\end{abstract}

\section{INTRODUCTION}

Seismic performance of ordinary reinforced concrete buildings in Japan is ensured in accordance with the Building Standard Law of Japan, pertinent regulations and design code of practice. The design procedure consists of two phases; checking the serviceability in the first phase and the safety in the second phase. The member strengths are to be made higher than the seismic actions by earthquake loading equivalent to a rare event based on linear analysis in the first phase. The ultimate lateral load carrying capacity is checked in the second phase against the required capacity for earthquake loading equivalent to a very rare event based on pushover analysis, taking the inelastic deformations and the collapse mechanism into account. A ductile beam-yielding collapse mechanism is selected mostly for medium- to high-rise reinforced concrete buildings. The effect of floor slabs is significant in the evaluation of beam ultimate flexural strengths, used in calculating the beam shear and column actions, which affects the design to ensure the selected overall mechanism.

\section{EFFECTIVE SLAB WIDTHS IN DESIGN PRACTICE}

The effective slab width in the elastic analysis for the first phase design is prescribed in the AIJ guidelines [1] as approximately one tenth of the beam longitudinal length, as shown in Figure 1(a). The effective slab width is evaluated mainly to derive the equivalent stiffness of T-beam section in the frame model for linear analysis. The effects of slab reinforcing bars on the flexural strength of beam is normally neglected during the first phase design.

The effective slab width is taken as a constant length of 1.0 meter on each side of the beam for the pushover analysis in the second phase design [2], as shown in Figure 1(b). The slab reinforcing bars within the effective width may be taken into account during the evaluation of ultimate flexural strengths of beams. Only the slab reinforcing bars in the upper chord have are taken into account for the evaluation of the beam flexural strength when the slab is in tension, while the slab bars in the lower chord are normally neglected because the anchorage lengths of the lower chord bars are regarded as insufficient to develop the full tensile strength in accordance with the normal practice of construction details.

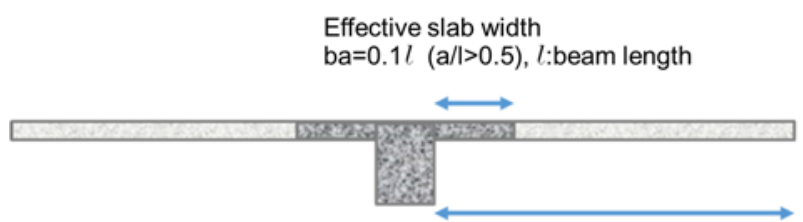

(a) Effective slab width for the first phase design

Upper slab rebars

In the range of $1.0 \mathrm{~m}$ width

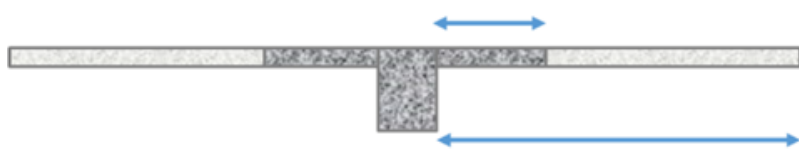

(b) Effective slab width for the second phase design

Figure 1: Effective slab width for beams in the Japanese seismic design code of practice.

The standard assumptions for the effective slab width described above have been used commonly in analytical models and strength evaluation, not only for static analyses of low and medium rise buildings in the two design phases, but also for time-history response analyses of high rise buildings.

\footnotetext{
1 Professor, Earthquake Research Institute, University of Tokyo, Japan, kabe@eri.u-tokyo.ac.jp

2 Associate Professor, Metropolitan University of Tokyo, Japan, tosikazu@tmu.ac.jp

3 Division Head, National Research Institute for Land and Infrastructure Management, Japan, fukuyama-h92ta@nilim.go.jp
} 


\section{EFFECTIVE SLAB WIDTHS FROM PAST TESTS}

The above assumptions for the effective slab widths, especially those for the second phase evaluation, are considered to be conservative estimates, which have been verified through many past experimental results, consisting mostly of one column subassemblage tests performed in the 1980s or early 1990s [3-7].

One span beam component tests were conducted with columns or loading blocks at the two ends, to which asymmetric moments were applied to induce the same rotations at both ends. Floor slabs were added to the longitudinal beam and anchored to the transverse beams at both ends, as shown in Figure 2. In this case, the effect of the slab would often be affected by the torsional rigidity and strength of the transverse beams. Axial elongation was constrained in some cases, which could cause other problems.

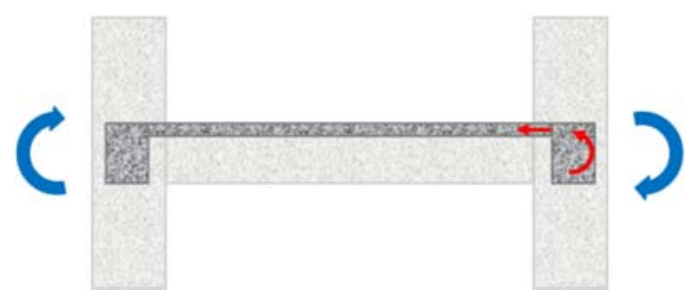

Figure 2: Beam component test with slab being anchored to transverse beams.

Some beam column joint assembly tests have been conducted with floor slabs, as shown in Figure 3. In this case the beam resistance with slabs became further complicated. Generally, the effective slab width is smaller during small drift amplitudes, which are often not much different with the design width prescribed as the guidelines. However, the effective width became gradually wider as the lateral drift increased, and could reach the full width of the slab at larger storey drifts. The resistance mechanism with slabs has been interpreted in literature [1] and as illustrated in Figure 4.

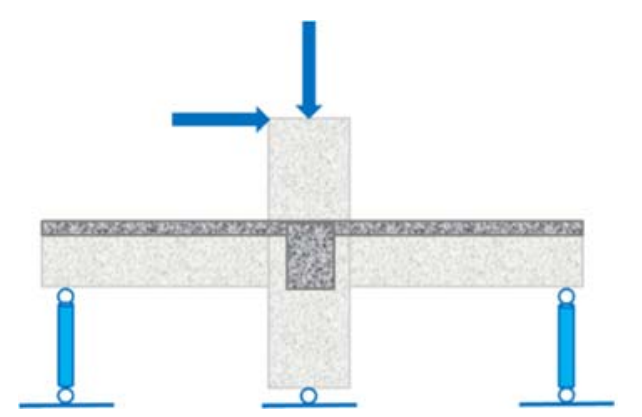

Figure 3: Beam column joint assembly test with slab.

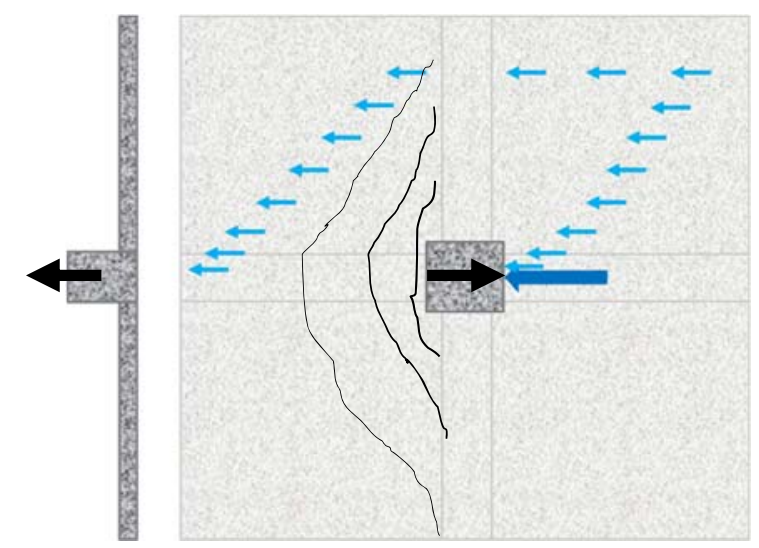

Figure 4: Plan and shear transfer mechanism of slab in beam column joint assembly tests.
Cracks in the slab face generally incline as shown in the figure, which means that the stress distribution at the side face of the transverse beam is not uniform. The stress becomes smaller as moving away from the column and the longitudinal beam. Even in the case with weak transverse beams, the slab bars at the far location could contribute to the flexural strength of the longitudinal beam owing to the shear transfer mechanism as follows. Torsional or horizontal deflections could be induced by yielding of slab reinforcement at the far location. However, it was found that the tensile forces in the slab reinforcement could be carried by the reinforcement on the other side and then transferred through the slab shear and concentrated to the compressive region on the column faces, as shown in the figure.

Most of these past tests on single members or assemblies indicated that the effective slab width could be very close to the full span width at the maximum strength. However, the design practices in Japan illustrated in Figure 1 have still been maintained, even after it has been concluded by the component tests that the ultimate strength calculated by the prescribed method is probably too conservative when compared to the observed maximum strength at the ultimate drift. This might be because the effective widths observed in the tests were gradually increasing with the inelastic drift amplitudes to attain the full widths, while the probable drift responses under design earthquake loading might be much less than the maximum strengths, especially during component tests. In some cases, maximum strengths were attained at relatively large deformations such as storey drifts of two to four percent radian, while the drift responses under very rare earthquakes are estimated to be around one percent radian in Japan. Also, the pattern of deformations in the test specimen, especially the inelastic axial elongation of the beam and slab, could be different from those in actual building structures.

On the other hand, the effectiveness of slabs on the beams has also been verified through recent laboratory tests on full-scale frame structures under static, pseudo-dynamic, or dynamic loading [8-11]. Because the slab effect was not the main research objective of these full-scale tests, the measurement on the local deformations and the strains in the slab bars were not always sufficient to verify analytical models generally. The effective widths were estimated from the comparison between the observed overall lateral strength and the frame analysis, by which the observed ultimate lateral capacities of the overall structure in term of overturning base moment corresponded to the calculated capacities not by assuming the code specified slab width but by assuming the full span slab width in most cases. It should also be noted that observed cracks in the slab did not incline as shown in Figure 4, but were parallel to the transverse beams. This has also been observed in damaged buildings where beam yielding occurred during recent postearthquake reconnaissance.

However, the conservative calculation by assuming narrow effective slab widths may not always be safe, because the smaller the assumed effective slab width could result in reduced safety performance from the viewpoint of ensuring flexural failure mode and/or beam yielding mechanism in the structure. Therefore, it is important to take in account the probable effective slab width during the seismic design calculations, especially, to ensure the selected failure modes of members and structures [12] in the assurance design of Japanese practice, or in the capacity design concept originated from New Zealand. Not only the ultimate strength but also the hysteretic relations of the beam-slab component could be different from the current models for time-history response analysis. Therefore, the seismic performance of beams with floor slabs need to be further verified through detailed tests and analyses. 


\section{NEW MODEL FOR SLAB-BEAM TEST}

Based on the review of past research, a series of frame assembly tests by a new loading method was planned and applied to validate the effective widths of floor slabs on the beam strength assumed in the current design practice. The project started as a part of national research projects for the consolidation of the Building Standard Law of Japan regarding the seismic design of high-rise buildings against long period earthquake motion in 2010 fiscal year. The research theme was adopted again from 2012 to 2014 for medium to low rise reinforced concrete buildings.

In the first 2010 project, a thirty-storey building was selected as a proto-type design for the test specimen, as shown in Figure 5. The specimens were designed and constructed representing part of interior frames with floor slab in a middle storey of the prototype building. Four columns from lower mid-height to upper mid-height with beams and floor slab of one span and two half spans in each direction were extracted as shown in the figure.

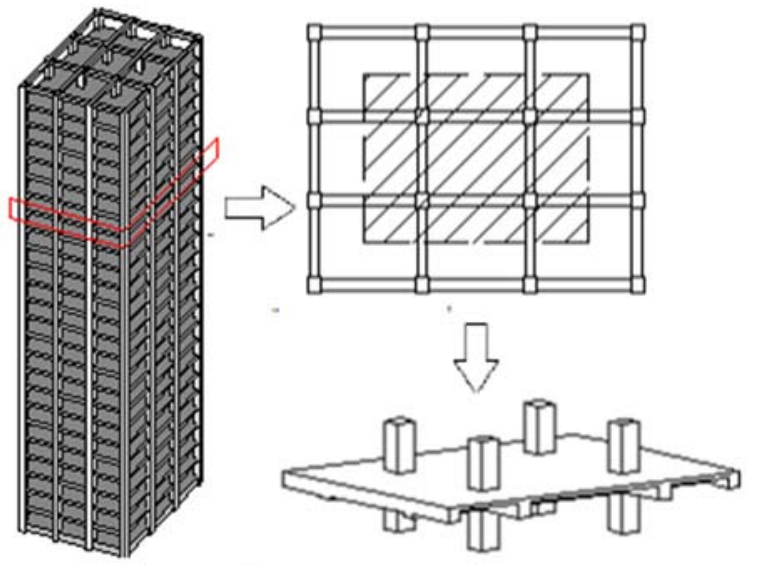

Figure 5: Assembly model for the specimen representing partial floor slab of mid-storey in high-rise building frame.

A series of three-dimensional frame tests were carried out under static cyclic lateral loading to investigate the contribution of the slab to the hysteretic behavior of beam-yielding frames [13]. A special loading set-up was developed to be used for the frame assembly. The four columns were loaded laterally and independently at mid-height of the upper storey and supported at mid-height of the lower storey with pin-fixed and pin-roller so that axial elongation of the beams and the slab would not be constrained by the lateral forces, as shown in Figure 6. Also, special consideration was made with respect to the boundary conditions at the mid-height columns so that the axial elongations in the beams were not constrained.

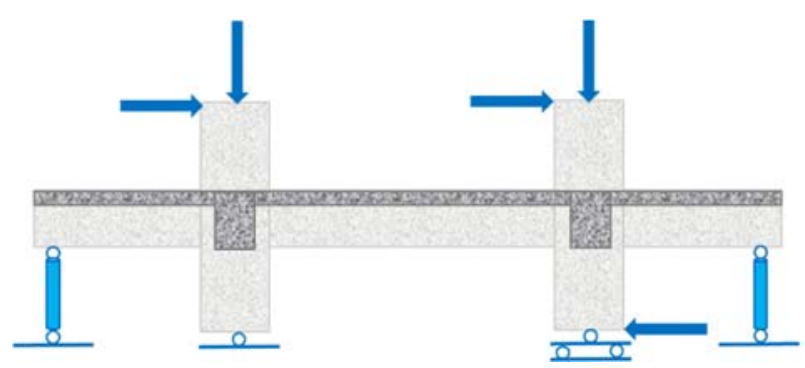

Figure 6: New component testing on serial beam column joint with slab allowing axial elongation.

Beam resistance including the slab might be different at interior and exterior beams. It is expected at the interior beams that axial elongation would occur due to cracking, as shown in Figure 7 , so that the slab reinforcement could be effective simultaneously with the beam reinforcement over the full width of slab as the reaction of the beam compressive force. On the other hand, the effectiveness of the slab at the exterior beam would occur at larger deformation due to the skewed shear transfer mechanism, as shown in Figure 4.

Two specimens were tested in the first 2010 test series with the only difference being the slab reinforcement ratios. The detailed test results have been reported in Japanese [14], while the test results of the second specimen (NO. 2) and the contribution of the slab to the beam resistance are discussed here in detail with the code specified calculated strengths.

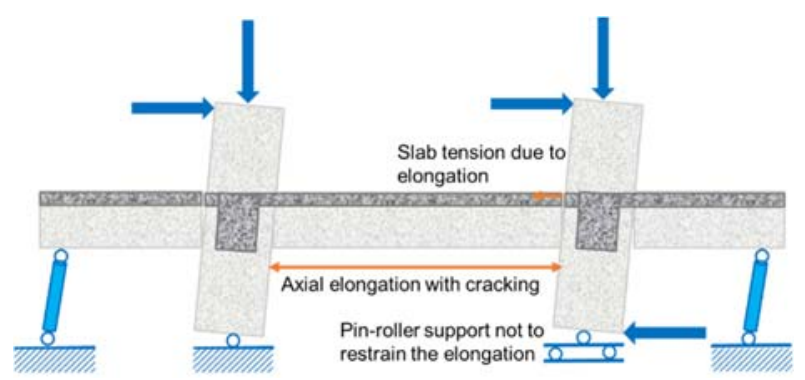

Figure 7: Expected mechanism of effective slab reinforcement at inner beam in the new frame testing.

\section{FIRST FRAME TEST WITH SLAB}

\section{Specimen}

The specimens were reduced by two-fifth scale from the sections and reinforcement details of the original design of the thirty-storey proto-type building to make the reinforcement diameter and spacing as equivalent as possible. The geometric sizes of the specimen are shown in Figure 8.

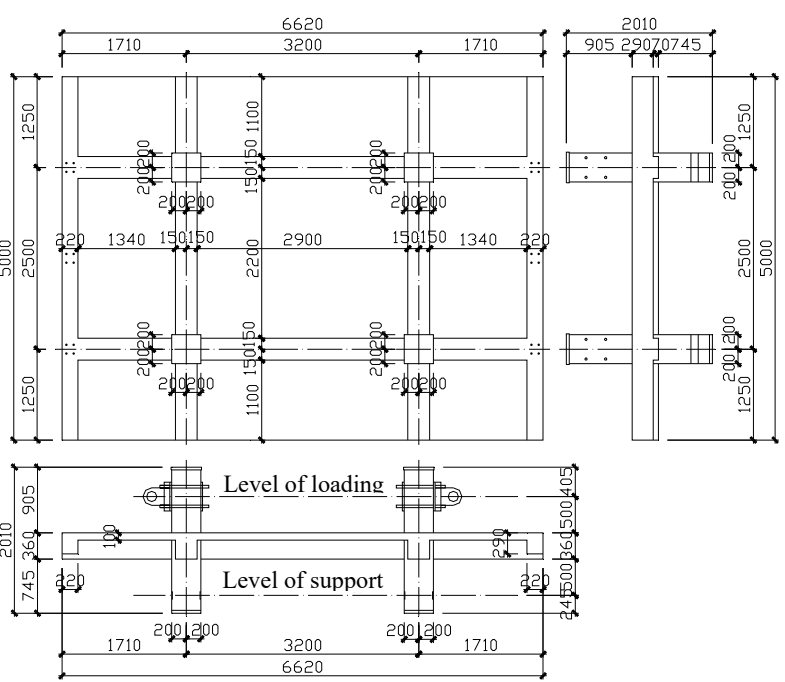

Figure 8: Geometry of the specimen.

The height of the specimen was $2010 \mathrm{~mm}$ with $1085 \mathrm{~mm}$ upper columns and $925 \mathrm{~mm}$ lower columns measured from the center of the beam, though the storey height was $1360 \mathrm{~mm}$ between the lower to the upper mid-height for loading. In the longitudinal direction, the center-to-center middle span length was $3200 \mathrm{~mm}$, while the center-to-end half-span was $1600 \mathrm{~mm}$. In the transverse direction, the center-to-center middle span was $2500 \mathrm{~mm}$, while the center-to-end half-span was $1250 \mathrm{~mm}$. The column sectional dimensions were $400 \mathrm{~mm}$ by $400 \mathrm{~mm}$. The width of the main beams was $300 \mathrm{~mm}$ and the depth was $360 \mathrm{~mm}$ in both directions. The transverse beams with sectional size of $220 \mathrm{~mm}$ by $290 \mathrm{~mm}$ were placed for loading at the two ends assuming the inflection point at the middle of the continuous beam span in both directions. The slab thickness was $100 \mathrm{~mm}$. 
The reinforcement details are shown in Figure 9. Deformed bars with the diameter of $6 \mathrm{~mm}$ (D6) and the nominal yield strength of $295 \mathrm{MPa}$ (SD295) were placed at the spacing of $75 \mathrm{~mm}$ at both upper and lower chords (2-D6@75) in both directions, while 2D6@150 in the first specimen (NO. 1). The main bars of the columns were 12-D16 (SD490) with the gross sectional ratio of $1.51 \%$ and the column hoops were 4-D6@50 (SHD685). The beams had 6-D16 at the top and 6-D16 at the bottom (SD490) as main bars with the gross sectional ration of $2.23 \%$, both arranged in two layers as shown in the figure. The stirrups in the beams were D6@50 (SHD685). The main bars of the columns and beams were welded to the steel plates at the ends. The concrete was cast in three stages, consisting of: 1) lower columns and joints, 2) beams and slabs, and 3) upper columns. The construction joints were placed about $75 \mathrm{~mm}$ away from the column faces with wire mesh.

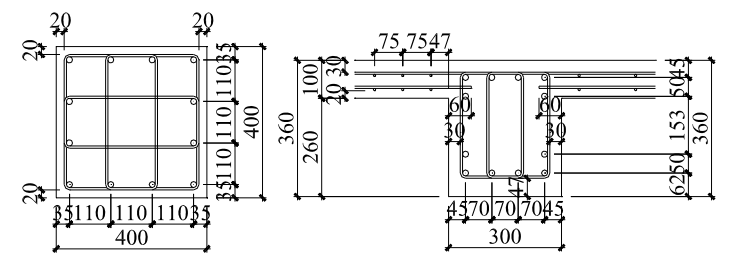

Colum main bar: 12-D16 Longitudinal beam main bar: 12-D16 Hoop: D6@50(SHD685) Stirrup: D6@75(SHD685)

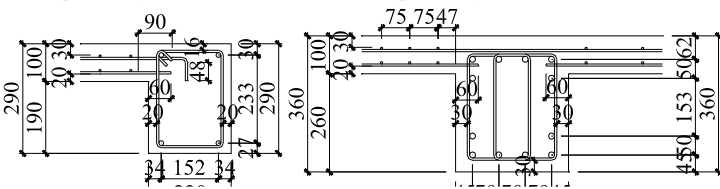

End beam main bar: 12-D13 Transverse beam main bar: 12-D16 Stirrup: D6@75(SD295)_Stirrup: D6@75(SHD685)

Slab main bar: 2-D6@75(SD295) for both directions

Figure 9: Reinforcement details in columns and beams.

\section{Material Properties}

Material tests were conducted at the date of testing. Relatively high strength materials were used for both steel and concrete in the specimen to represent the design of the proto-type high-rise building. The actual material properties from the tests are shown in Table 1 and Table 2. D16 bars used as the longitudinal reinforcement for beams and columns had a distinct yield plateau region in the stress-strain results, while the yield plateau of the D6 bars used as the reinforcements of slabs and hoops was not apparent.

Table 1: Concrete material properties.

\begin{tabular}{l|r|r|c|c}
\hline $\begin{array}{c}\text { Concrete } \\
\text { cast part of the } \\
\text { specimen }\end{array}$ & $\begin{array}{r}\text { Nominal } \\
\text { Strength }\end{array}$ & $\begin{array}{c}\text { Comp. } \\
\text { strength }\end{array}$ & $\begin{array}{c}\text { Strain at } \\
\text { peak } \\
\text { strength }\end{array}$ & $\begin{array}{c}\text { Elastic } \\
\text { Modulus }\end{array}$ \\
\cline { 2 - 5 } & $\mathrm{N} / \mathrm{mm}^{2}$ & $\mathrm{~N} / \mathrm{mm}^{2}$ & $\left(\times 10^{-6}\right)$ & $\mathrm{N} / \mathrm{mm}^{2}$ \\
\hline Lower column & $\mathrm{Fc60}$ & 74.6 & 3016 & 35530 \\
\hline Beam and slab & $\mathrm{Fc48}$ & 58.7 & 2730 & 31420 \\
\hline Upper column & $\mathrm{Fc48}$ & 56.0 & 2549 & 31170 \\
\hline
\end{tabular}

Table 2: Reinforcement material properties.

\begin{tabular}{l|r|r|r|c}
\hline $\begin{array}{c}\text { Nominal } \\
\text { diameter and } \\
\text { strength of } \\
\text { steel bars }\end{array}$ & $\begin{array}{c}\text { Yield } \\
\text { strength }\end{array}$ & $\begin{array}{c}\text { Yield } \\
\text { strain }\end{array}$ & $\begin{array}{c}\text { Elastic } \\
\text { Modulus }\end{array}$ & $\begin{array}{c}\text { Max. } \\
\text { strength }\end{array}$ \\
\cline { 2 - 5 } D16(SD490) & 550.2 & 3277 & 204990 & 707.86 \\
\hline D6(SD295) & 371.5 & 3981 & 185907 & 541.36 \\
\hline D6(SHD685) & 712.8 & 5840 & 186305 & 910.09 \\
\hline
\end{tabular}

\section{Loading Method}

The loading setup is illustrated in Figure 10(a) and an overview photo is shown in Figure 10(b). The two columns on the south side were supported with pin ends assuming the inflection points as mid-height of lower columns, while the two columns on the north side were supported with pin-roller ends, so that the axial deformations would not be restrained by the axial forces caused by the beam and slab elongation increasing with the inelastic deformations. The transverse beams at both ends of the outside half-spans were supported in the vertical direction with the pin-end jacks and the load cells simulating the inflection points at the mid-span. H-shaped steel beams of $200 \mathrm{~mm}$ by $200 \mathrm{~mm}$ size were appended to increase the stiffness and strength at the top of both end beams additionally. A constant axial load of $900 \mathrm{kN}$ was applied at each top of the four columns using vertical actuators with pin-connected to the column at the bottom end and roller support at the top end of the actuators, which could move freely by four 2-D roller supports attached to two big steel beams on the top. Seismic loads were applied to the tops of the columns using four jacks and to the pin roller supports at north side were also loaded by two jacks. The pin supports were fixed to the concrete base.

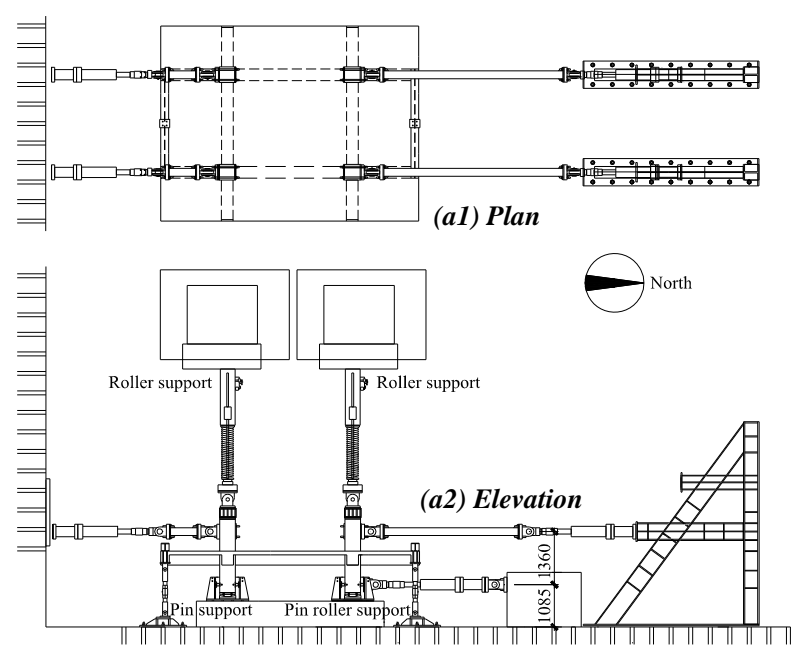

(a) Plan and elevation of loading set up

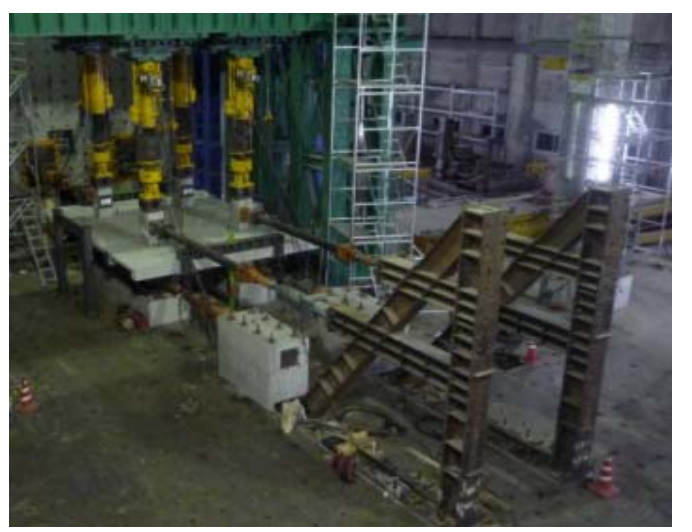

(b) An overview photo of loading set up

Figure 10: Loading set up at structural testing laboratory, Building Research Institute, Tsukuba.

The details of the column pin and pin roller supports at the column bases are shown in Figure 11(a). The steel footing of pin support was fixed on the foundation, while the steel footing of pin roller support was just placed on a smooth plastic plate so that transversal movement was allowed. Steel rods of $75 \mathrm{~mm}$ diameter welded on the steel footing were attached to the column faces to apply horizontal force or reactions. Two smooth steel face plates curved with a radius of $750 \mathrm{~mm}$ were manufactured. One was connected to the column bottom, and 
another one was just put under it and could move freely with the rotation of the column. However, during the test these supports did not work as well as anticipated due to: (i) unexpected movement in larger cyclic deformations, (ii) the friction, and (iii) the lack of precision in manufacture, which caused an eccentric reaction to the axial load, as shown in Figure 11(b). The correction of these errors is discussed later.

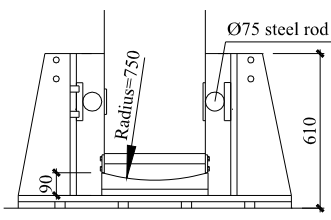

(a1) Pin support

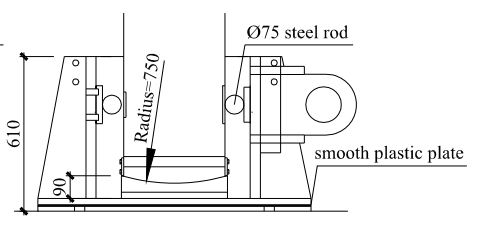

(a2) Pin roller support (a) Pin support and pin roller support

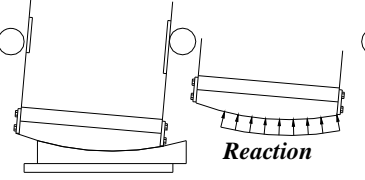

(b1) Expected mechanism

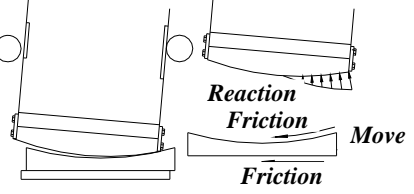

(b2) Actual mechanism (b) Expected and observed reaction mechanism

Figure 11: Pin support and pin-roller support

To simulate the vertical loads of high-rise buildings, an axial force of $900 \mathrm{kN}$ was applied to each column and kept constant automatically by the four vertical actuators. The averaged compressive stress in the column section was 0.084 times the concrete strength. Then static lateral cyclic forces were applied with six lateral oil jacks. The south jacks and the north jacks were operated independently. The north jacks of upper and lower storeys were operated to keep the same level but in the opposite directions by the common oil pressure, while the storey drift angles of the south columns were synchronized to those of the north columns controlled manually through the instantaneous feedback data from the lateral displacement gauges at the upper and lower loading level of each column. Number of cyclic loading was selected as common with the other component tests in the project. Enough large numbers, such as ten times of cyclic load reversals in 0.5 and 1.0 percent storey drift angles, were selected based on the simulation of the responses of high rise buildings under design long period of motion with long duration. However, the first specimen showed sufficient ductile behavior in flexural even under ten repetitions of cyclic loading. Therefore, for the second specimen reported here was loaded in accordance with the history shown in Figure 12 , consisting of two cycles at each peak drift. The maximum drift was amplitudes of 0.06radian for the first specimen, while terminated at 0.03 radian for the second specimen by observing the damage levels regarded as nearly the reparable limit state. Then the second specimen here was repaired and tested again in the ERI laboratory in the next year.

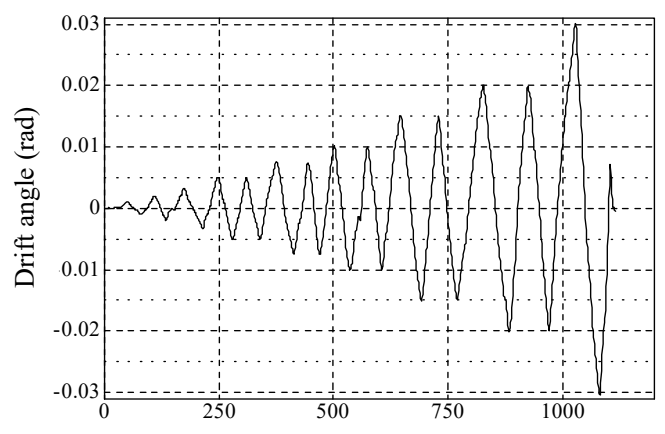

Load step number for measuring

Figure 12: History of storey drift ratio.
At the end of fiscal year of 2010, the East-Japan Earthquake occurred and heavy damage was observed in old RC and steel buildings, while many reinforced concrete high-rise buildings subjected to the long period motions survived with minor or less structural damages. It may be concluded that the damage was generally minor or slight and much less serious than alerted by some researchers.

The project on the slab effect was once terminated due to the damage of laboratory, and another project started from 2012 to 2014 for medium to low rise buildings using normal concrete and steel. A total of seven specimens were tested hereafter to compare the cases with normal/high strength materials, frames with/without slab, end span frame under varying axial load, and thick slab with void.

\section{Instrumentation}

The locations of displacement gauges and wire strain gauges for measurement of local deformations and strains in reinforcement are shown for the west frame in Figure 13. Lateral displacements of each column were measured at the top and the bottom of loading levels, and also at the floor level, from which lateral deflection of the columns and overall elongations were derived. Local axial deformations, (or elongations), and rotations were measured on the surfaces of the slab and beams and also on the column side faces using displacement gauges and sliding pipes with universal joints at each end. Relatively dense measurement was planned on the slab surface at the critical sections to derive slab effects by the distribution of axial elongations at the sections. The strains were measured on the reinforcement in the beam and the slab not only at the critical sections but also at points away from the critical sections.

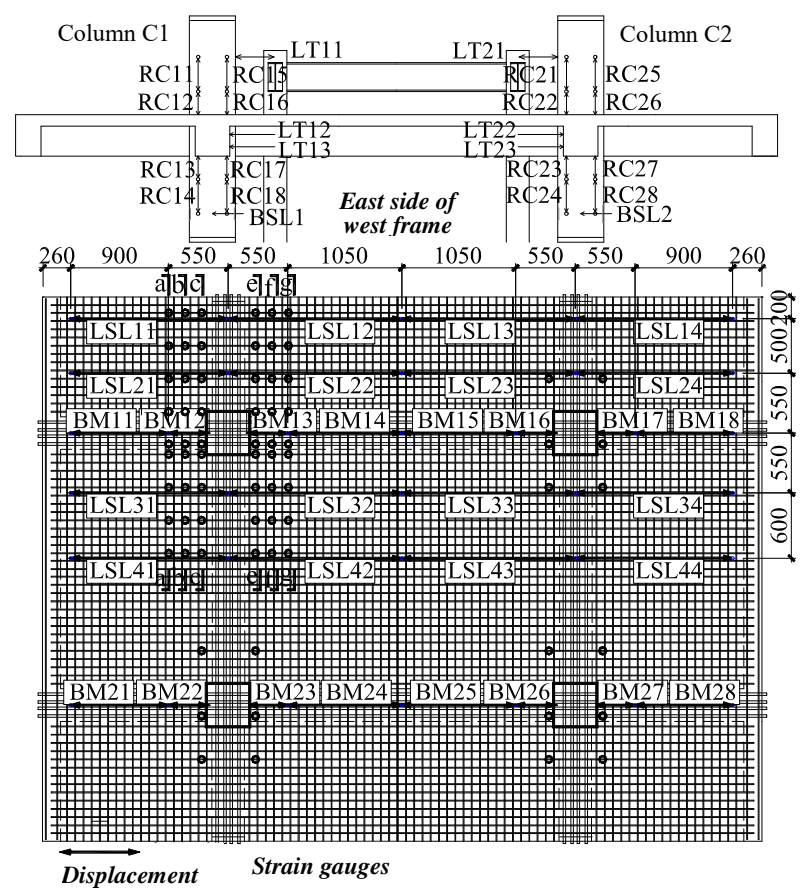

Figure 13: Location of displacement and strain gauges.

\section{TEST RESULTS AND DISCUSSIONS}

\section{Evaluation of the Overall Strength}

As indicated above in Figure 11, the column moments could be induced by the eccentric reactions at the bases, which were intended to be pin support. The fixing moments at the bases must be estimated and quantified anyhow, which are to be subtracted from the measured lateral resistance by the load cells, to identify the actual resistance of the specimen or the 
beam strength. The fixing moment could be of significant amplitude for rigorous estimation of the slab effects on the beam strength. In that case, proper evaluation of the column base moments and correction of the lateral resistance becomes essential. The column base moments were identified from the measured local deformations of the columns as follows.

The strains measured in the lower column main reinforcing bars were no more than $1026 \mu$ both in tension and compression until 0.02 drift ratio. Therefore, elastic curvature distribution $\phi(x)$ could be assumed in the columns, which were proportional to the moment profile. Referring to Figure 14, the moment profile along the column height $M(x)$ is expressed by equation (2), using the shear force in the columns $F$ and the column base moment $M$ в. The curvature may be calculated as shown in equation (3) in proportion to the moment using the elastic column bending stiffness EI. The rotation angles of the two segments $\theta_{1}$ and $\theta_{2}$ can be formulated by integrating the curvature distribution $\phi(x)$ along the column as equations (4) and (5). The ratio of the upper and lower rotations can be given from the local deformations measured during the test as given by equation (6). Therefore, the base moment $M \mathrm{~B}$ can be derived from the measured local deformations.

$$
\begin{aligned}
& M(x)=(0.5-x) F-M_{\mathrm{B}} \\
& \left.\emptyset(\mathrm{x})=\left\{(0.5-x) F-M_{\mathrm{B}}\right)\right\} / E I \\
& \theta_{1}=\int_{0}^{0.2} \emptyset(x) d x=\left(0.08 F-0.2 M_{\mathrm{B}}\right) / E I \\
& \theta_{2}=\int_{0.2}^{0.5} \emptyset(x) d x=\left(0.045 F-0.3 M_{\mathrm{B}}\right) / E I \\
& \left(0.08 F-0.2 M_{\mathrm{B}}\right) /\left(0.045 F-0.3 M_{\mathrm{B}}\right)=\theta_{1} / \theta_{2}
\end{aligned}
$$

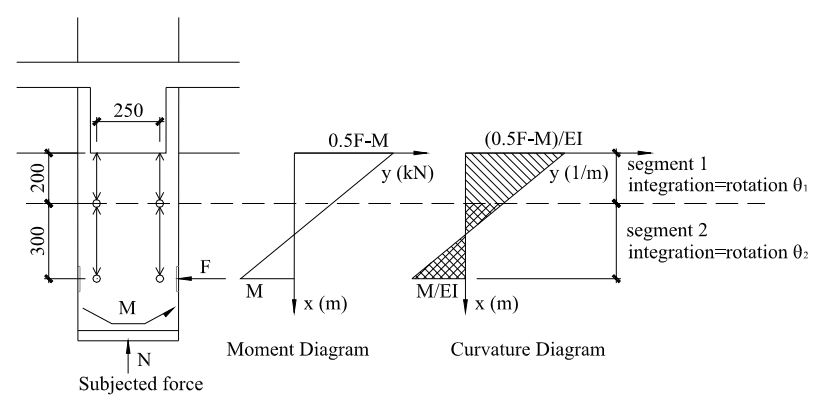

Figure 14: Estimate model of base moment.

The base moments of the south-west and north-west columns were calculated as described above for the second specimen. The relation between the base moments and the lateral drift are shown in Figure 15(a) and (b). To confirm the accuracy of above estimation method, another method was also applied to compute the base moment using the measured strains of the column reinforcement. It was then confirmed that both methods of estimation would give similar base moments. After the determination of the column base moments, the whole moment distribution of the specimen could be identified. It should be noted that the upper bound of the base moment for one column is limited as $0.5 D \times N=0.5 \times 0.4 \times 900=180(\mathrm{kNm})$, when the reaction force is acting at the bottom end of the column.
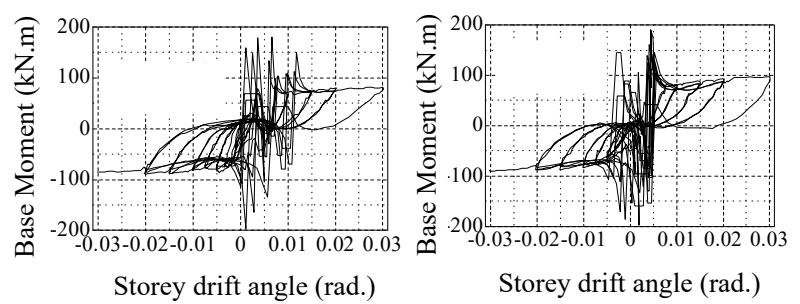

(a) South column in west frame

(b) North column in west frame

Figure 15: The additional base moment derived from measured local deformations for a column.
In cases of the test series that followed from 2012 to 2014, the details at the base supports were improved so that the base moments in the columns were negligible small and above correction became unnecessary.

\section{Observed Hysteretic Relations}

The overall hysteretic response is shown in Figure 16 as the relations between storey shear force and storey drift ratio. The shear force is the sum of the lateral shear forces of the four columns directly derived from the load cells at the column tops. Therefore, the resistance includes the additional strength due to the column base moment as described above. The maximum observed strength attained was equal to $2224(\mathrm{kN})$ at a peak drift angle of 0.03 radians.

The calculated strengths are also shown in the figure, which considers the additional base moment as described above. The ultimate strength calculated by the code specified design procedure of phase II was $1610(\mathrm{kN})$ using the design effective slab width of $400 \mathrm{~mm}$ in $2 / 5$ scale and corresponding to $1.0 \mathrm{~m}$ for full scale on one side slab as illustrated in Figure 1(b) and shown in Figure 16 with a dotted line. In this case, only the upper chord slab reinforcing bars within the width were considered. The ultimate strength calculated by the same code specified design procedure of phase II was $1964(\mathrm{kN})$ assuming the full effective slab width of $1050 \mathrm{~mm}$ on one side for $2 / 5$ scale specimen and taking both the upper and lower chord slab reinforcing bars into account, which means all of the slab reinforcement was considered. In both cases, the material yield strengths in Table 2 and code specified design equations were used for calculation of the flexural strength of the T-shaped beam section, which provided close agreement with the flexural analysis. It should be noted that the observed resistance exceeded the code specified strength even at less than $1 / 100$ storey drift and the full slab-width calculation at less than 1/75.

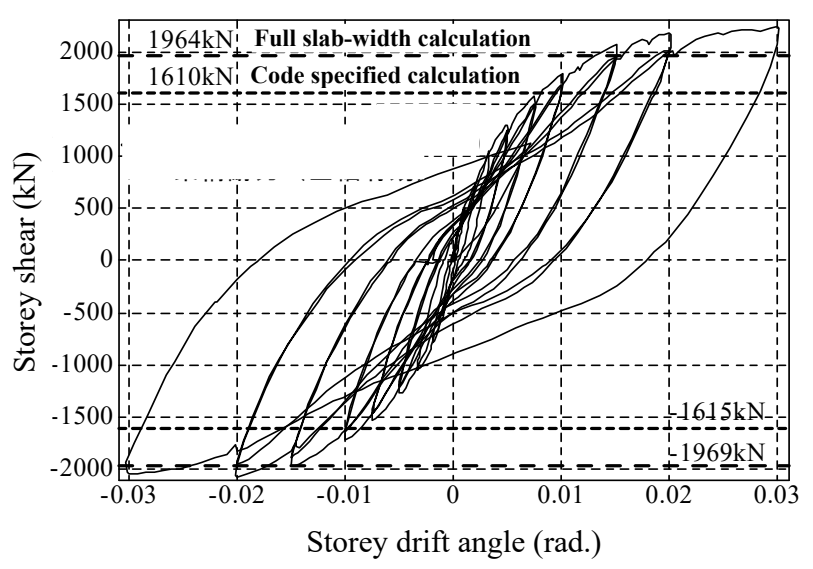

Figure 16: Overall hysteretic relations.

\section{Observed Cracks}

During the first loading cycle with an amplitude of $1 / 1000$ radians, flexural cracks initiated vertically from the bottom at the south ends of the inner beams close to the joint face. The total storey shear force attained $193 \mathrm{kN}$ in the positive direction defined as from south to north direction. Similar cracks at the bottom of the opposite beam ends at $-123 \mathrm{kN}$ in the negative direction. All of the initial cracks were observed at about $75 \mathrm{~mm}$ away from the column face due to the construction joints. At the first peak of $3 / 1000$ drift cycles, inclined cracks (shear type) were observed to have developed in the bottom of beam in the middle span. However, there were almost no obvious inclined cracks from the beam bottom on side half-spans in the whole loading process. This is because the inflection point of the inner span beam was moved to hogging moment side for slab participation, causing smaller shear span ratio that tend to generate shear cracks. The crack pattern observed in the east 
beam side at the $1 / 200$ cycle and $1 / 100$ cycle are shown in Figure 17(a) and Figure 17(b), respectively.

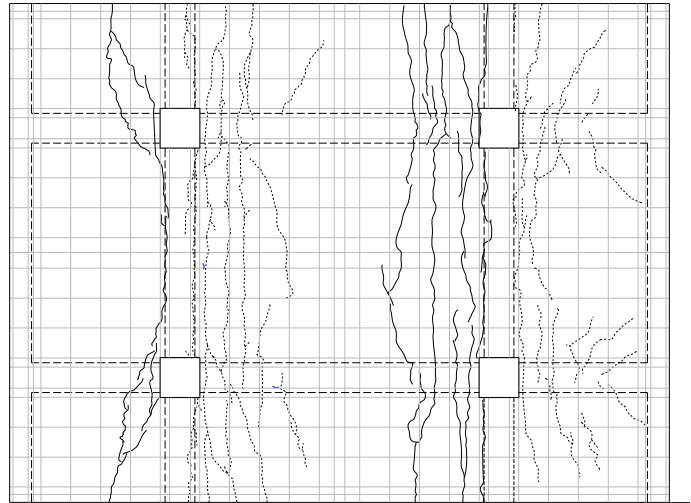

Cracks in $1 / 200(\mathrm{rad})$

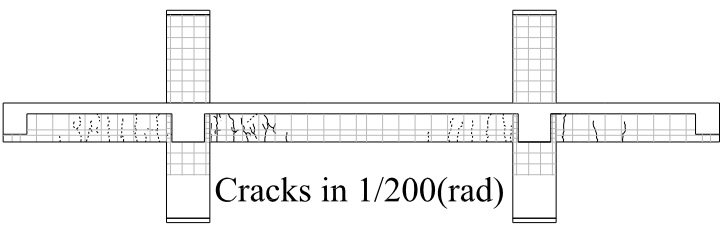

(a): At 1/200 storey-drift.

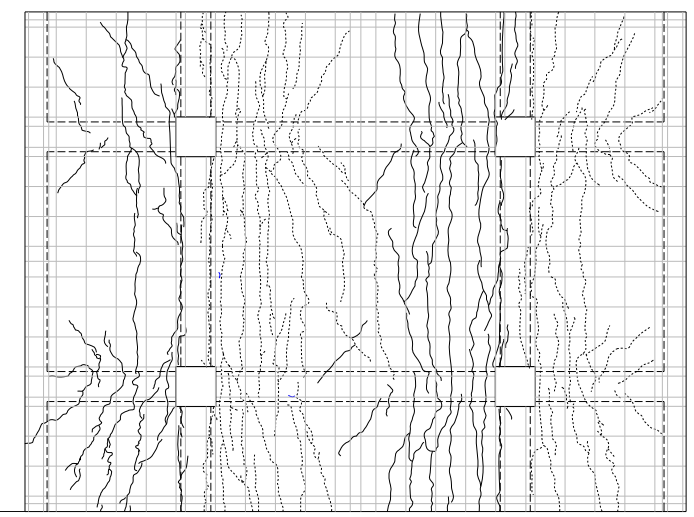

Cracks in $1 / 100(\mathrm{rad})$

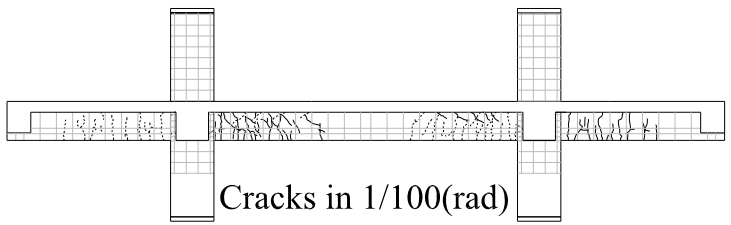

(b): At 1/100 storey drift.

Figure 17: Cracks at 1/100 and 1/200 storey-drifts.

During the $1 / 100$ cycle, cracks were observed on the column side faces above the joints, and the number and width of cracks increased with increasing storey drift. However, no cracks were found on the column side faces below the joints during the entire test. Moreover, it was observed that the inclination of the upper column cracks was larger than the lower columns, which was more obvious in larger storey drifts. Bending moments occurred at the base of all the columns, which could be proved by the measured deformations and the strains of reinforcements as shown afterwards. The cracking of the column was minor due to high axial load and high flexural strength.

The outer half-spans of the transverse beams also had cracks on the beam side near joints after the 1/1000 drift cycle. However, these cracks were also exactly at the place of construction joints. In addition, the width and number of cracks on the transverse beam remained almost unchanged until the 1/50 drift cycle. The cracking might be due to torsion from the slab, though the boundary condition might have been stiff enough until larger drifts. After the 1/50 cycle, inclined cracks started to develop and wide in the transverse beams.

Cracking of the slab was observed on the top face at the peak of the 2/1000 drift cycle. The initial cracks on the slab face immediately penetrated to the whole width of the slab and the cracking could also be observed at the bottom face. The cracks on the inner span were perpendicular to the longitudinal beams or parallel to the transverse beams, while the cracks on the outer half-spans were inclined, as shown in the figures. On the other hand, the cracks on the slab that propagated into the inner beams tended to incline vertically, while those in the outer span beams remained vertically parallel. These might be because of the boundary conditions and associated resistance mechanisms, which were different between the inner and outer spans.

Cracks were recorded at the time of their occurrence during the first stage of loading in smaller storey drift, while the crack widths were measured manually at each peak of drift cycles in the positive and negative directions and also at the unloading point when the lateral resistance returned to nearly zero. The cracks were recorded all over on the upper surface of the slab, while partially on the frame members, such as the bottom surface on east side, the side and the bottom faces of the longitudinal beams and the transverse beams and around the columns in the east side frame.

Maximum crack widths measured in the inner span beam at the peak drifts and the unloading points are shown in Figure 18 in relation with the positive and negative storey drift levels. The maximum crack widths measured at the peaks were roughly $0.3 \mathrm{~mm}$ at the drift of $1 / 200 \mathrm{rad}, 0.6 \mathrm{~mm}$ at $1 / 100,1.3 \mathrm{~mm}$ at $1 / 67$, $2.5 \mathrm{~mm}$ at $1 / 50$. The crack widths were initially proportional to the storey drift, but increased more rapidly during larger drifts.

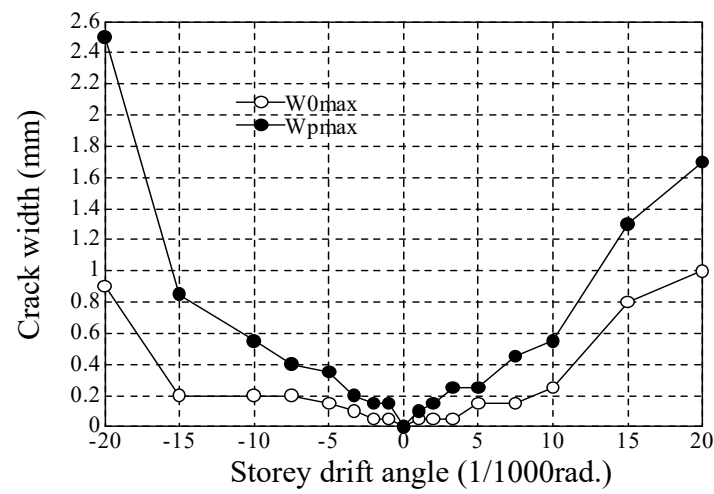

Figure 18: Maximum crack widths for the inner span beam measured at peak drifts and unloading points.

The crack widths measured at the unloading points are referred to as residual crack widths, although they are not exactly similar to the residual crack widths observed during dynamic responses with the same peak amplitudes applied in shake table tests and post-earthquake observations. The residual crack widths for the inner span beam measured at the unloading points are also shown in the figure. The residual crack widths were roughly half or one third of the maximum crack widths. Minor cracks were observed in the upper columns, but not in the lower ones, probably due to the unexpected fixing moment at base supports.

Detailed observation of other cracking may be applied in damage evaluation after earthquakes, although scale effects must be properly accounted for. The observed crack widths might general be larger than estimated from past test on beams, probably due to free axial elongations. The residual damages observed after the test, unloaded from the peak drift of 3/100, are shown in Figure 19(a) and Figure 19(b). 


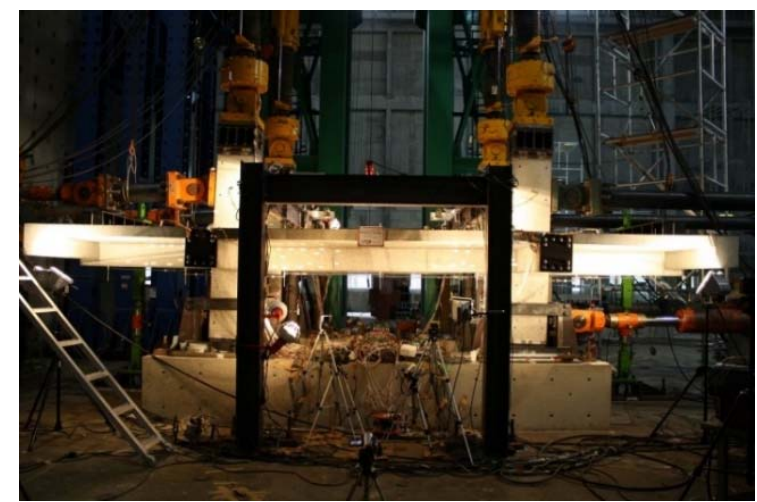

(a) East side view of the specimen after the test
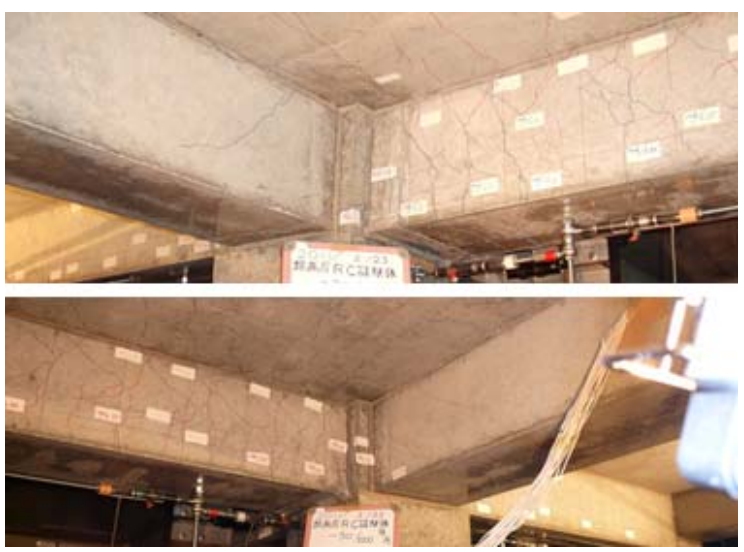

(b) Lower beam column joints after the test

Figure 19: Damages observed after the test (unloaded from the peak drift of 1/30).

\section{Local Deformations and Strains}

Flexural deformations of the inner beams, east and west, are shown with the storey drift in Figure 20. Axial elongations were measured at upper and lower faces to derive bending rotations of four segments (Seg1-Seg4) along the beam, as shown in the illustration above the plot in the figure. Similar distributions were measured in the east and west beams. The rotations at end segments (Seg1 and Seg4) increase in proportion to the storey drift, even after 1/100rad, while those at mid segments (Seg2 and Seg4) become constant after 1/100rad. The rotations at end segments were symmetric in positive and negative loading, with minor differences probably due to the dislocation or movement of the inflection point at the mid-span due to the large difference of the flexural strengths at the end with the effect of the slab.

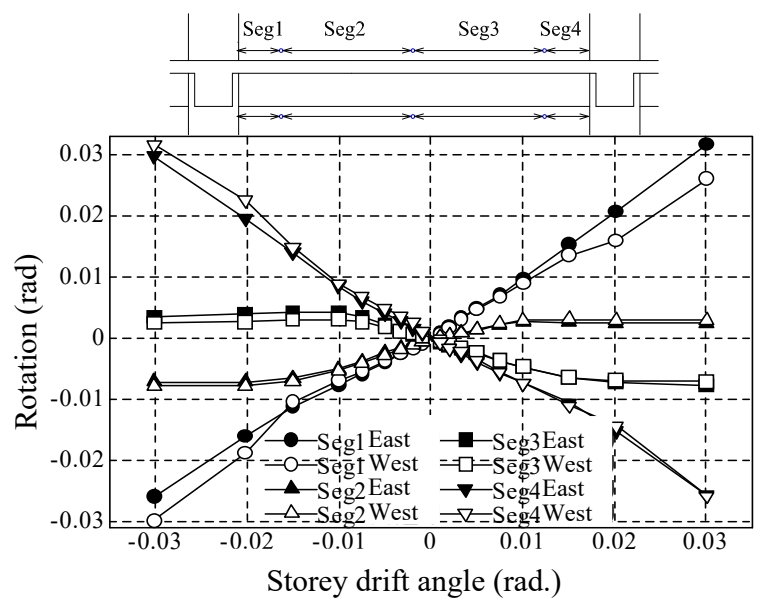

Figure 20: Beam rations measured at four segments in the inner beams.
Distributions of the longitudinal elongations in the inner span measured on the slab surface of the south half span and the west half region are shown in Figure 21. The elongations are shown as unit length in $\mathrm{mm}$ at each negative peak drift when the slab is in tension. Maximum elongation was observed at the location of the beam and relatively smaller at the edge or at the center of slab, though 80 percent even at the edge, which may be regarded as nearly uniform distribution across the critical section. This is also the case through the transition from elastic to inelastic response, which indicates that the slab reinforcement could be uniformly effective at full span to the yield and ultimate strength of beam.

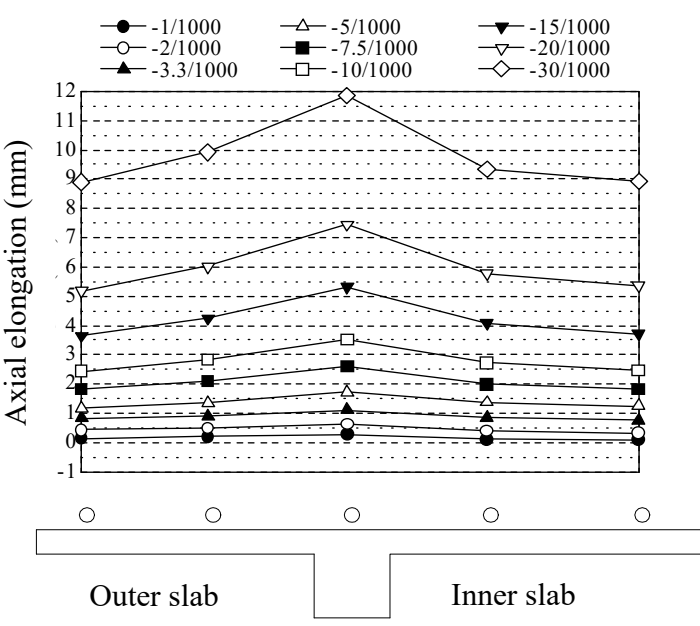

Figure 21: Distributions of axial deformations on the slab for south and west half span of the inner beam.

Deformations and strains measured for the columns are shown in Figure 22 and Figure 23, indicating that the column response was essentially elastic. This is an additional evidence for the accuracy to derive the fixed end moments, which have been discussed previously.

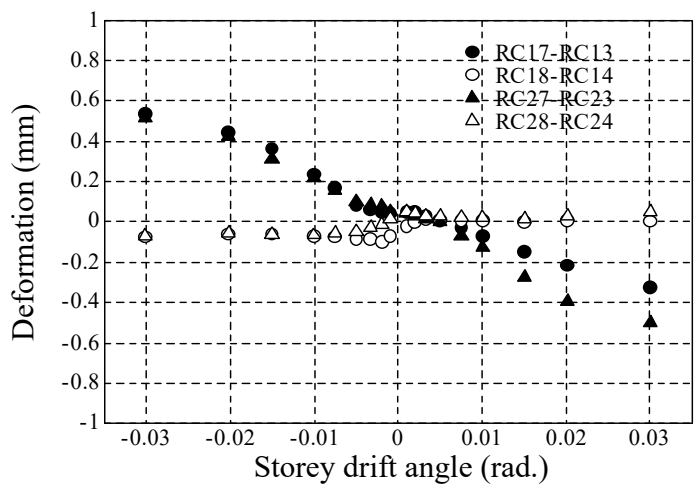

Figure 22: Deformation of columns.

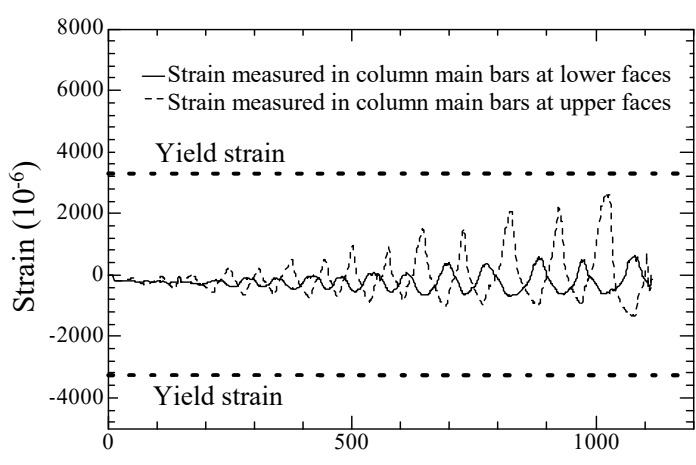

Load step number for measuring

Figure 23: Strains measured in column main bars at the critical faces of the beam-column joints. 
To verify the accuracy of strain measurements in the beam and slab reinforcement, which will be shown afterwards, the curvatures at the beam ends (Seg1 and 4) are compared for those derived from the strains measured in beam main bars, shown in white marks, and also those derived from the axial deformations shown with black marks in Figure 24. The strains may be smaller than average due to the effect of concrete bond, although reasonable correlations are generally observed. The strains measured in the beam reinforcement at the beam column joints were well below the yield strain and the damage to the beam column joints seemed to be minor with no diagonal cracks though it was difficult to observe directly due to the transverse beams.

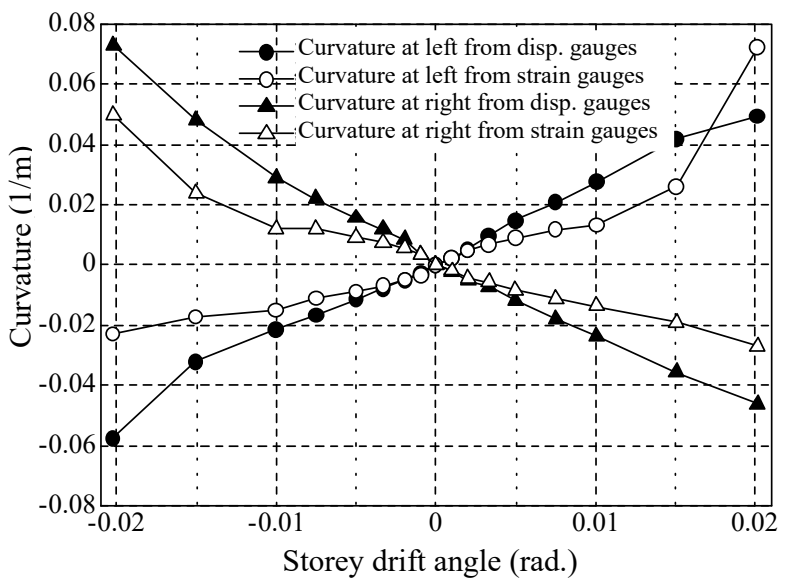

Figure 24: Rotations of inner span beam and storey drift.

Strains measured in the slab reinforcement at the critical sections of the inner span beam are shown in Figure 25 at three different locations at the distance of $0 \mathrm{~mm}, 150 \mathrm{~mm}$ and $300 \mathrm{~mm}$ inside from the critical section at the column face line, $50 \mathrm{~mm}$ apart from the side face of the transverse beams. The slab reinforcement started to yield at a storey drift of $1 / 300 \mathrm{rad}$. The yielding was also observed in the lower chord slab reinforcement, although it has been neglected in design due to an insufficient anchorage length of 10d. The strain and stress distributions at the section ( $\mathrm{f}-\mathrm{f}$ ) for peak drifts are shown in Figure 26 and Figure 27, respectively. It may be concluded that most of the slab reinforcement attained near yield stress $\left(371 \mathrm{~N} / \mathrm{mm}^{2}\right)$ almost uniformly at the critical section until a storey drift of $1 / 100$.

The observations and measurement for local deformations and strains indicate that the slab reinforcement could probably be working at stress levels close or equal to the yield stress of the steel material along the critical section with the full span width even around the yielding deformation of the beams.

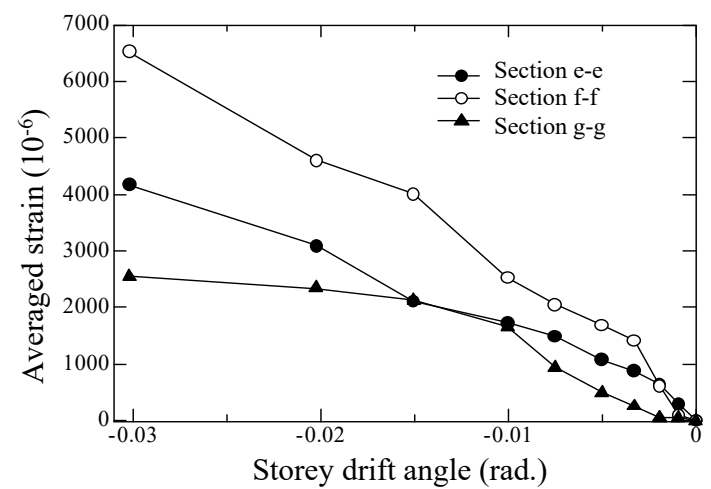

Figure 25: Strains averaged for the slab reinforcement at the critical sections of the inner span beam with the storey drift.

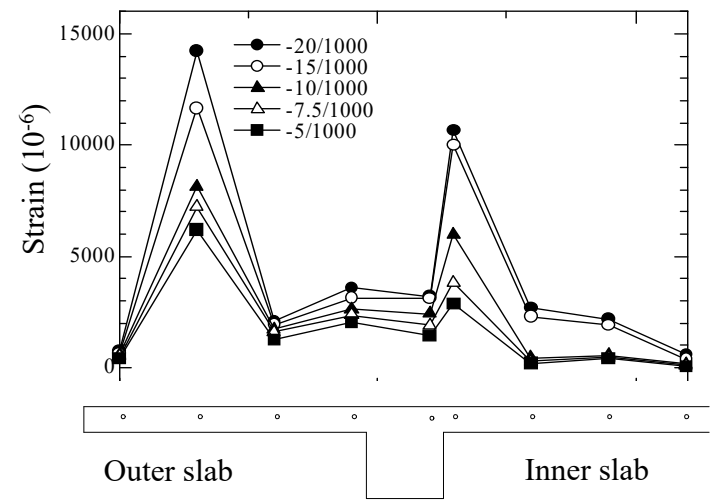

Figure 26: Strains measured in the slab reinforcement at the critical sections of the inner span beam at peak drifts.

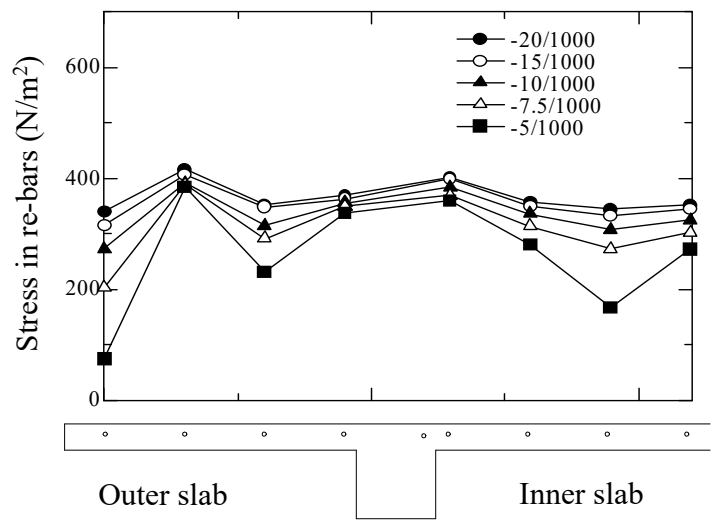

Figure 27: Stress distributions of the slab reinforcement along the critical section derived from strains measured at peak drifts.

\section{Evaluation of Effective Slab Width}

Flexural strengths calculated using the full width of the slab at each critical section of the beams were compared with the measured moment resistance identified from load cells and corrected with the additional column base moments, as shown in Figure 28. Four force deformation lines with circles show the measured moment resistance in positive direction: (1) the red solid line shows the moment at inner span with the slab in tension, (2) the red dashed line shows the moment at the inner span with the bottom edge in tension, (3) the black solid line shows the moment at the outer span with the slab in tension and (4) the black dashed line shows the moment at the outer span with the bottom edge in tension. In addition, the calculated strength using the full span width of the slab and all of the reinforcement is shown for both bending directions with the slab in tension (solid blue line) and the bottom edge in tension (blue dashed line).

The moment at the inner span with the slab in tension attained the calculated strength at a drift of $1 / 100$, and also the moment at the inner span with the bottom edge in tension exceeded the calculated moment by 1.5 times. On the other hand, the moments at the outer span increased gradually. In particular, the moment with the slab in tension was much smaller at $1 / 100$, although it finally reached close to the calculated strength at $3 / 100$.

These results might be due to the insufficient support conditions at the end of the outer slab. The transverse steel beams were placed on and beneath the outer span end, by which axial reaction forces were transferred to the transverse beams and the longitudinal beam ends. The beams were supported with one vertical jack and load cell at each end of the outer span. The two 
jacks were not working with oil pressure but just used as pin support rod initially tightened up by torque wrench. However, the pin-connection devices at both ends of the supporting jacks had some looseness. Also the jack was placed only at the center of whole span so that the stiffness of the transverse beams also might have been insufficient to fix the vertical displacement at the end of longitudinal beams. These insufficient details were revised in the succeeding test series from 2012 to 2014.

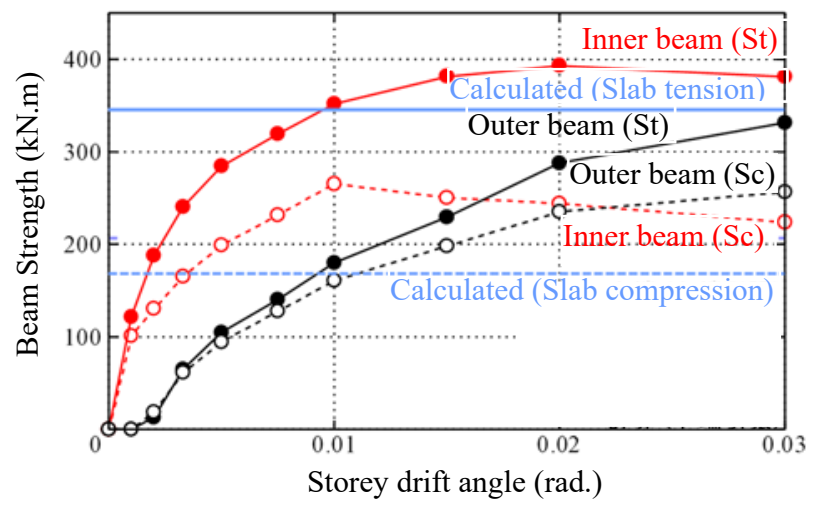

Figure 28: Measured and calculated beam flexural strengths.

\section{CONCLUSIONS}

A series of frame assembly tests were conducted to investigate the effective slab width when calculating the ultimate strengths of beams in reinforced concrete buildings. The test results of a specimen is reported and discussed in detail, from which the following conclusions may be drawn:

(1) The observed crack patterns, measured local deformations and strains in slab reinforcement strongly indicate that the slab reinforcement was close to yielding along the full width of the critical section, at the storey drifts of $1 / 100 \mathrm{rad}$. and around the yield deformation of the beams

(2) The flexural resistance of the inner beam measured at the drift of $1 / 100$ exceeded the flexural strength calculated by using the full effective slab width and all of the reinforcement at the upper and lower chord. Therefore, the beam flexural strength would be much higher than the code calculation, which might affect the strength hierarchy to ensure a ductile beam-yielding mechanism.

(3) The effectiveness of slab in relation to the storey drift was obviously influenced by the boundary conditions of the specimen and loading. Cracks in the inner span of the elongating beam produced straight cracks on the slab parallel to the transverse beam, while the cracks in the outer span were inclined perpendicular to the radiating forces from the reaction points.

(4) The findings on the slab effectiveness are partially dependent on the new loading system adopted for the frame-floor assembly test reported herein. Although the setup allowed for axial elongations of the beams and floor slabs, some of the details needs further improvement.

\section{ACKNOWLEDGEMENTS}

This research was funded as part of national research projects for the consolidation of the Building Standard Law of Japan in 2010. The frame tests were conducted at the Large Size Experiment Laboratory of Building Research Institute, Tsukuba, supported by many related researchers with ERI, BRI, NILIM and Ohbayashi-Gumi LTD. Contribution of Deng Xuan, formerly with ERI, is gratefully acknowledged. This paper is based on the draft presented at RSNZ-JSPS workshop held in Waiheke, September 8-10, 2016. The first drafts from Japan were much improved owing to kind reviews by NZ side.

\section{REFERENCES}

1 Architectural Institute of Japan (2009). "AIJ Standard for Structural Calculation of Reinforced Concrete Structures". Article 8: Basics of Structural Analysis, AIJ, 63-64 (in Japanese).

2 Building Center of Japan (2007). "Guidelines for Structural Standard Requirements on Buildings". BCJ, 620-663 (in Japanese).

3 Suzuki N, Otani S and Kobayashi Y (1984). "ThreeDimensional Beam-Column Subassemblages under Bidirectional Earthquake Loadings". Proceedings of the $8^{\text {th }}$ World Conference on Earthquake Engineering (8WCEE), San Francisco, Prentice-Hall, 6: 453-460.

4 Joglekar M et al. (1988). "Full Scale Tests of Beam-Column Joints" in US-Japan Research: Earthquake Effects on Reinforced Concrete Structures". Special Publication SP84, American Concrete Institute (ACI), USA, 271-304.

5 Zerbe HE and Durrani AJ (1985). "Effect of Slab on the Behavior of Exterior Beam to Column Connections". Report No. 30, Department of Civil Engineering, Rice University, Houston, Texas.

6 French CW and Boroojerdi A (1989). "Contribution of RC Floor Slabs in Resisting Lateral Loads". ASCE Journal of Structural Engineering, 115(1): 1-18.

7 Qi X and Pantazopoulou SJ (1991). "Response of RC Frame under Lateral Loads". ASCE Journal of Structural Engineering, 117(4): 1167-1188.

8 Kabeyasawa T, Shiohara H and Otani S (1984). "US - Japan Cooperative Research on RC Full-Scale Building Test, Part 5: Discussion on Dynamic Response System". Proceedings of the $8^{\text {th }}$ World Conference on Earthquake Engineering (8WCEE), San Francisco, Prentice-Hall, 6: 627-634.

9 Kabeyasawa Toshimi, Kabeyasawa Toshikazu, Matsumori T, Kabeyasawa Toshinori and Kim Y (2008). "Full-scale dynamic collapse tests of three-storey reinforced concrete buildings on flexible foundation at E-Defense". Proceedings of the $14^{\text {th }}$ World Conference on Earthquake Engineering (14WCEE), Beijing, China, S15-002:8pp.

10 Kabeyasawa Toshimi, Kabeyasawa Toshikazu, Matsumori T, Kim Y and Kabeyasawa Toshinori (2009). "Full-Scale 3-D Shake Table Tests on Reinforced Concrete Building Structures at E-Defense". Proceedings of the $4^{\text {th }}$ International Conference on Construction Materials (CONMAT09), August 24-26, Nagoya, 1-16.

11 Nagae T et al. (2010). "Test Results of Four-Storey Reinforced Concrete and Post-Tensioned Concrete Buildings, The 2010 E-Defense Shaking Table Test". Proceedings of the $15^{\text {th }}$ World Conference on Earthquake Engineering (15WCEE), Lisbon, Portugal, Paper No. 3870:10pp.

12 Dhakal RP, Peng BHH, Fenwick RC, Carr AJ and Bull DK (2014). "Cyclic Loading Test of a RC Frame with PrecastPrestressed Flooring System". ACI Structural Journal, 111(4): 777-788.

13 Kabeyasawa Toshikazu et al. (2011). "Static Loading Test of a Three-dimensional Frame Simulating High Rise Reinforced Concrete Building Structures Subjected to Many Cyclic Loads, Part 1 and Part2". Proceedings of AIJ Annual Meeting, 741-744.

14 Kabeyasawa Toshimi, Kabeyasawa Toshikazu, Xuan D and Fukuyama H (2015). "Frame Test on Effects of Slab to Beam Strength in Reinforced Concrete Buildings". AIJ Journal of Structural Engineering, 61B: 103-110. 